\title{
ESCRITURA, MEMÓRIA E ASSOCIAÇÃO: PROCESSOS DE CRIAÇÃO DE POEMAS POR ALUNOS RECÉM ALFABETIZADOS
}

\section{WRITING, MEMORY AND ASSOCIATION: CREATION \\ PROCESSES OF POEMS BY NEWLY LITERATE STUDENTS}

\section{Eduardo Calil \\ Universidade Federal de Alagoas}

RESUMO: A partir da Genética Textual e da Linguística da Enunciação, este estudo analisa dois processos de criação de poemas escritos por duas díades de alunos recém alfabetizados, em contexto de sala de aula. A análise das filmagens destes processos identificou tipos de relações associativas (SAUSSURE, 1987; SUENAGA, 2004) feitas pelos escreventes e o modo como estas relações e articulam com os conteúdos recuperados da memória de cada um. O processo coenunciativo sugere a formação de redes associativas que indicam a gênese da escritura destes poemas.

PALAVRAS-CHAVE: Escola. produção de texto. Autoria. Criatividade. Poesia.

ABSTRACT: From Textual Genetics and Linguistics of Enunciation, this study analyzes two processes of creating written poems by two dyads of newly literate learners in the context of the classroom. The

\footnotetext{
* Possui mestrado em Educação pela Universidade de São Paulo (USP) e doutorado em linguística pela UNICAMP. É professor do Programa de Pós-graduação em Letras e Linguística e do Programa de Pós-graduação em Educação e coordenador do Laboratório do Manuscrito Escolar na Universidade Federal de Alagoas (UFAL). Maceió, Alagoas, Brasil. E-mail: eduardocalil@hotmail.com
} 
analysis of the filming of these processes identified types of associative relations (SAUSSURE, 1987; SUENAGA, 2004) made by students and how these relations are articulated with contents retrieved from the memory of each one. The co-enunciative process suggests the formation of associative networks that indicate the genesis of these poems' writing.

KEYWORDS: School. Textual production. Authorship. Creativity. Poetry. 


\section{ESCRITURA, MEMÓRIA E ASSOCIAÇÃO: PROCESSOS DE CRIAÇÃO DE POEMAS POR ALUNOS RECÉM ALFABETIZADOS}

Dans une foule de cas, il est difficile de classer une combinaison d'unités, parce que l'un et l'autre facteurs ont concouru à la produire, et dans des proportions qu'il est impossible de déterminer.

(SAUSSURE, 1982, p. 173.)

\section{INTRODUÇÃO}

A Genética Textual (GRÉSILLON, 1994; BIASI, 2011) defende que o manuscrito literário é um objeto semiótico de dupla ordem, cujo caráter escritural faz dele, ao mesmo tempo, um objeto verbal e não verbal ${ }^{1}$. Nesta

1 O manuscrito pode ser entendido como toda peça escrita, tenha ela um valor literário ou não. Seu estatuto, em nosso campo de investigação, pode ser dado por sua dimensão inconclusa, inacabada e processual. As marcas gráficas espalhadas sobre a superfície da folha de papel (rasuras, riscos, borrões, desenhos, reformulações...) seriam índices que caracterizariam este objeto como um "texto em construção", diferenciando-o do texto pronto, isto é, do produto final gerado pelo conjunto de materiais (rascunhos, esboços, versões, notas, etc.) que o antecedeu. 
peça, interagem, de um lado, aquilo que o escrevente leu, estudou, vivenciou, suas anotações e esquemas, arranjados na sucessividade dos elementos linguísticos encadeados na cadeia sintagmática de cada palavra, cada frase, cada linha... e, de outro, a simultaneidade visual e fixa do que já foi escrito, dos traços, rabiscos, setas, borrões, cores, rasuras...

Isso supõe que sua escritura sofre, tanto os efeitos do funcionamento da língua e da memória, quanto a submissão a sua condição espacial e recursiva, cujo fim é fazer um texto - ainda que possa não ser necessariamente concretizado. Portanto, apesar de seu caráter efêmero e heterogêneo, todo manuscrito tem em seu horizonte, virtualmente, um ponto de chegada, uma unidade "textual" feita, simultaneamente, através de uma dimensão linear, recursiva e não linear².

É a investigação deste caráter processual do "texto em construção" (FENOGLIO, 2007; MAHER, 2009) que tem sido o foco de interesse da Genética Textual em muitos estudos sobre o texto escrito na escola (BORÉ, 2010; DOQUET, 2011; FRADET, 2010; FIAD, 2013, dentre outros), sobretudo depois dos trabalhos inaugurados por Fabre (1990), ao destacar a importância do manuscrito (e da rasura) do aluno, indicando não somente as especificidades da escritura escolar, mas também suas semelhanças e diferenças com a escritura literária (FABRE-COLS, 2004).

Apesar de significativamente diferente das etapas da escritura literária (BIASI, 2011), a gênese da criação textual na sala de aula também envolve o caráter semiótico multimodal da escritura. Essa gênese não se constitui pelo intenso processo de escritura de um escrevente experiente ou profissional, poeta ou linguista, responsável pela produção de diversos materiais que poderão constituir um dossiê genético ${ }^{3}$, mas pelas práticas didáticas e dinâmicas interativas entre professor e seus alunos.

2 Desde o início dos anos 80 (LEBRAVE, 1983), o estatuto, a diferença e a fronteira entre "manuscrito", "rascunho" e "texto" tem sido colocada em questão. Discussões mais recentes podem ser encontradas em Fenoglio (2007) e Mahrer (2009). Neste trabalho, seguindo argumentação apresentada em Calil (2008), iremos tratar o texto produzido em sala de aula como "manuscrito escolar".

3 Conforme Grésillon (1994), o "dossiê genético" reúne o conjunto de materiais (cartas, rascunhos, manuscritos, anotações, agendas, diários, etc.) produzidos ao longo do processo de escritura de uma obra. 
Para estes estudos sobre a escritura escolar, o manuscrito e sua gênese irão igualmente compor um sistema semiótico multimodal, marcadamente sócio-histórico, cuja dinâmica criativa depende da inter-relação de uma grande diversidade de fatores históricos, sociais, individuais, linguísticos, cognitivos, interacionais, comunicacionais, didáticos e técnicos. Apesar de situados em ambiência didática e não literária, estes fatores contribuem para a caracterização das condições de produção e podem favorecer o estabelecimento de relações associativas constituídas tanto pelo modo como a língua se articula, quanto por aquilo que o escrevente recupera de sua memória, delimitando a direção da escritura e o potencial de sua inventividade.

Nosso estudo pretende avançar nesta direção, destacando o processo criativo de poemas escritos por alunos recém alfabetizados. A partir de um procedimento metodológico até o momento pouco utilizado por pesquisadores engajados neste campo de estudo, elegemos a escritura escolar "em ato", isto é, durante sua efetivação em seu contexto real, quando interagem o professor e seus alunos durante propostas de produção de texto.

Trataremos o processo de escritura escolar e seu produto como um só objeto de estudo, respeitando as dimensões do aqui (espaço) e agora (tempo) circunscrito no jogo enunciativo entre o falar e o escrever em sala de aula. Para mostrar como as dimensões deste objeto se inter-relacionam, analisaremos os processos de criação textual através das relações associativas (SAUSSURE, 1987), conforme propostas por Suenaga (2004) e o papel da memória dos locutores, escreventes novatos.

\section{RELAÇÕES E MEMÓRIAS NO PROCESSO DE ESCRITURA}

Ao mesmo tempo em que as palavras são escritas, encadeadas e articuladas linearmente, uma após a outra, o que já foi escrito, sua fixidez e seu caráter gráfico oferece a possibilidade de se rasurar uma frase, um parágrafo, um título escrito há 2 meses ou de se inserir uma epígrafe anotada quando se estava lendo, por exemplo, as fontes manuscritas de Saussure. Ao se fazer isso, além de ser necessário garantir o sentido de cada frase, a partir das possibilidades da língua, também é preciso articular e manter o sentido ao 
longo do texto em construção - o que supõe não só manter uma unidade entre as palavras e frases, mas também preservar certas propriedades do gênero textual, constituídas sócio-historicamente.

Este é um dos aspectos mais importantes do processo de escritura, sendo o retorno sobre o texto em curso e suas marcas (dentre elas, as rasuras) um fenômeno privilegiado que excede os limites da cadeia sintagmática. Tarefa árdua, cuja aprendizagem exige anos de experiência e prática (KELLOGG, 2008), envolvendo, tanto o funcionamento da língua e o conhecimento do escrevente, quanto o desenvolvimento da memória, a recuperação de conteúdos e informações e a geração de ideias que serão postas e articuladas no texto durante seu processo de escritura.

Do ponto de vista linguístico, Saussure, ao discutir a questão do arbitrário e do valor, toca na relação entre língua e memória. A "limitação do arbitrário" dependeria, segundo o autor, da relação associativa sintagmática e da associação associativa ${ }^{4}$, sendo a primeira delimitada pela cadeia sintagmática e a segunda pela memória do sujeito falante. Se a primeira delimita o arbitrário através do encadeamento dos elementos linguísticos no sintagma, a segunda o delimita a partir do que está "no cérebro" do falante.

Isso é o que diz no capítulo $\mathrm{V}$ da segunda parte do CLG:

De um lado, no discurso, os termos estabelecem entre si, em virtude de seu encadeamento, relações baseadas no caráter linear da língua, que exclui a possibilidade de pronunciar dois elementos ao mesmo tempo. Estes se alinham um após outro na cadeia da fala. Tais combinações, que se apoiam na extensão, podem ser chamadas de sintagmas. [...]

Por outro lado, fora do discurso, as palavras que oferecem algo de comum se associam na memória e assim se forma grupos dentro dos quais imperam relações muito diversas. [...]

4 Estas relações corresponderiam ao que Saussure chamou de "relação horizontal" e "relação vertical". 
Vê-se que essas coordenações são de uma espécie bem diferente das primeiras. Elas não têm por base a extensão; sua sede está no cérebro; elas fazem parte desse tesouro interior que constitui a língua de cada indivíduo. Chamá-las-emos relações associativas.

(SAUSSURE, 1987, p. 142-143).

Naquele momento, sabia-se muito pouco sobre a memória humana e Saussure apenas a mencionou de passagem, indicando em pontos esparsos do CLG que são os elementos da língua que fazem parte do que entendia por memória:

Se pudéssemos abarcar a totalidade das imagens verbais armazenadas em todos os indivíduos, atingiríamos o liame social que constitui a língua. Trata-se de um tesouro depositado pela prática da fala em todos os indivíduos pertencentes à mesma comunidade, um sistema gramatical que existe virtualmente em cada cérebro ou, mais exatamente, nos cérebros dum conjunto de indivíduos, pois a língua não está completa em nenhum." (SAUSSURE, 1987, p. 21, grifos nossos.) É ouvindo os outros que aprendemos a língua materna; ela se deposita em nosso cérebro somente após inúmeras experiências. (...) A língua existe na coletividade sob a forma duma soma de sinais depositados em cada cérebro, mais ou menos como um $\underline{\mathrm{di}-}$ cionário cujos exemplares, todos idênticos, fossem repartidos entre os indivíduos.".

(SAUSSURE, 1987, p. 27, grifos nossos.)

A presença dos termos "imagens verbais", "sistema gramatical", "soma de sinais", "dicionário", entre outros termos e expressões, indica a possível dificuldade de Saussure em definir o que seria o "tesouro interior", constituído por "séries mnemônicas virtuais" (SAUSSURE, 1987, p. 143). 
Contudo, uma observação importante pode ser feita. Se o "tesouro" dependeria do que "se deposita em nosso cérebro somente após inúmeras experiências", parece ser legítimo supor que o falante não poderia fazer associações entre elementos não pertencentes ao sistema de sua língua. Por exemplo, para o falante brasileiro seria impossível constituir séries mnemônicas virtuais entre termos de uma outra língua, nem mesmo associar um termo de sua língua com outro termo de outra língua. Mas, ainda assim, não é claro o que seria exatamente a "experiência" do falante para Saussure. Talvez se possa considerar que ela seria o modo particular como cada falante se insere nas práticas culturais e discursivas de sua sociedade, em dado momento sócio-histórico. Sabemos, por exemplo, não ser possível um falante de língua portuguesa de hoje falar ou fazer associações, como um falante de língua portuguesa em 1290, quando foi instituída como língua oficial do Reino de Portugal. As associações estariam relacionadas ao que se constituiu enquanto "tesouro" individual, sendo recuperadas pelo falante de sua memória, a partir de sua experiência enquanto sujeito submetido à cultura e constituído sócio-historicamente.

As relações associativas horizontais e verticais, por sua vez, seriam responsáveis pela delimitação do arbitrário na língua, como Saussure procurou mostrar através de diferentes exemplos. Talvez o mais famoso seja aquele apresentado na página 175, com a palavra enseignement.

Suenaga (2004), partindo deste exemplo, reinterpreta estas relações, propondo três tipos de combinações entre o significado e o significante:

Tipo 1, associação por significante e significado: a relação associativa sintagmática decorre de um mecanismo morfológico em que há comunidade ou agrupamento de morfemas. Este tipo de associação pode ser exemplificado por:

• “ensinar”, “ensinamos", “ensino”... que formam uma associação por partilhar a mesma raiz.

- “ensinamento", “carregamento", “armamento”... são associados pelo sufixo comum "mento" que nominaliza um verbo. 
Tipo 2, associação por significado: quando há uma associação sobre o plano do significado, isto é, quando há uma relação de contiguidade semântica entre os termos.

- "ensinamento", "aprendizagem", "educação", "escola", "universidade”... são associados por sinonímia ou por relação entre parte-todo.

Tipo 3, associação por significante: trata-se de uma associação ao nível do significante, quando há comunidade ou agrupamento por semelhança fônica.

- "ensinamento", "elemento", "casamento", "armamento"... cuja associação se dá unicamente sobre o plano da sonoridade.

Não iremos entrar na delicada questão do "arbitrário absoluto" e do "arbitrário relativo", mas vale destacar que a delimitação do valor de um termo é dada pelas relações do tipo 1 (delimitação sintagmática) e do tipo 2 (delimitação associativa), restritas ao caráter "gramatical" do sistema, limitativas do arbitrário, enquanto que o tipo 3 (delimitação fônica) teria um caráter "simbólico", permitindo, segundo a proposta de Suenaga, a partir da reflexão de Gadet (1989), o "alargamento" do arbitrário. Partindo destas considerações sobre as relações associativas e os tipos de combinações entre significado e significante, discutiremos o papel da memória em processos de criação textual de escreventes novatos.

Temos aí dois objetos inter-relacionados, mas cuja fronteira não parece fácil de ser demarcada. De um lado, o princípio da linearidade, do qual um texto, por ser escrito, não pode abrir mão. De outro, o caráter semiótico multimodal específico do processo de escritura em sala de aula, do qual faz parte não somente o texto escrito, mas igualmente as condições didáticas e interacionais. Para a análise que desenvolveremos, estas relações precisam ser tratadas em consonância com o processo de escritura constituído em tempo e espaço reais, isto é, com o fato de se estar escrevendo um texto em sala de aula.

Interpretaremos estes tipos de relações como suporte para se entender o processo criativo de poemas. Portanto, partiremos da hipótese de que, qual- 
quer que seja o tipo de relação identificada, ela não se faz de um termo ao outro, nem se limita à dimensão do sintagma. Na medida em que o processo de escritura escolar forma um sistema semiótico multimodal particular, envolvendo tanto a dimensão uniespacial e sucessiva, quanto a dimensão visual e simultânea, estabelecida sob a condição didática e interacional, as relações associativas (sintagmática, semântica e fônica) permitem a constituição de um rede de relações construídas coenunciativamente, cujo horizonte textual é o seu produto. Neste sentido, o "texto em construção" sofre as pressões das condições de produção estabelecida através da interação entre professor e alunos, que irá interferir na produção de uma unidade semântica e textual, ainda que subjetiva e virtual. Esta unidade estaria cerceada pelas propriedades do gênero textual em questão, assim como pelos elementos recuperados da memória do escrevente, articulados e encadeados na materialidade linear, espacial e recursiva da folha de papel.

\section{PROCESSOS E MANUSCRITOS EM DUAS PROPOSTAS DE PRODUÇÃO DE POEMAS}

A afirmação feita acima sobre a dupla dimensão do objeto de investigação eleito, envolvendo a articulação entre o processo em tempo e espaço real e seu produto - o manuscrito escolar - justifica-se sobretudo pelo procedimento metodológico de caráter etnográfico, adotado e desenvolvido desde o início dos anos 90 (CALIL, 1991, 1994). Através da filmagem de propostas de produção textual em salas de aula, quando alunos organizados em díades são solicitados, por seus professores, a escreverem um único texto, pudemos recuperar a dinâmica interacional, cotidiana e espontânea entre os locutores e o que caracterizamos como "manuscrito oral" (CALIL, 2008, p. 47). Este oximoro preserva uma das principais propriedades de nosso objeto de estudo, não se restringindo nem ao que foi "escrito", nem ao que foi "falado", embaralhando a aparente e enganosa dicotomia que estes termos carregam.

A especificidade deste objeto permitiu associar o diálogo e os aspectos visuais (gestos, olhares, aproximações do professor e colegas, registro do ambiente físico de sala de aula, etc.) ao ato específico de se escrever um tex- 
to, formando um sistema semiótico multimodal que constitui o processo de criação sob estas condições. Este sistema permite recuperar a gênese da escritura dos alunos envolvidos, como por exemplo, identificar quem falou pela primeira vez uma palavra ou um verso e as reformulações e rasuras sobre este elemento, constituído coenunciativamente, até sua forma definitiva fixada na folha de papel.

\subsection{Poema de cada dia e sua coleta}

O projeto didático "Poema de Cada Dia” foi desenvolvido entre os anos de 2000 e 2001, em uma escola situada na periferia de Maceió, atendendo a alunos de 11 anos de idade, que já haviam repetido um ou dois anos escolares, filhos de pais pouco escolarizados, de recursos econômicos bastante limitados. Durante a execução deste trabalho como parte das aulas de língua portuguesa, foram lidos, declamados e interpretados aproximadamente 40 poemas de poetas diversos (CALIL, 2001). A cada 15 dias, em média, alunos de um $2^{\circ}$ ano do Ensino Fundamental eram agrupados em díades e o professor solicitava a produção de um poema.

Tabela 1: relação de propostas e poemas inventados

\begin{tabular}{|l|l|l|l|}
\hline $\mathbf{N}^{\circ}$ & Data & Poema & Escreventes \\
\hline & $14 / 09 / 2000$ & Raridade & Valdemir e Antenor \\
\hline $01 / 11 / 2000$ & A Viagem & Valdemir e Antenor \\
\hline $23 / 11 / 2000$ & O pesadelo & Valdemir e Antenor \\
\hline $30 / 11 / 2000$ & As meninas & Valdemir e Antenor \\
\hline $18 / 05 / 2001$ & Amarelo & Valdemir e Roberto \\
\hline $31 / 05 / 2001$ & A formiga & Valdemir e Roberto \\
\hline $24 / 08 / 2001$ & No escuro & Valdemir e Maria \\
\hline $30 / 08 / 2001$ & Crescendo/Azul & Valdemir e Maria \\
\hline $14 / 09 / 2001$ & Quem vem me salvar & Valdemir e Maria \\
\hline $28 / 09 / 2011$ & Cidade & Valdemir e Maria \\
\hline $05 / 10 / 2001$ & O nada e a estrada & Valdemir e Wellington \\
\hline
\end{tabular}


$16 / 10 / 2001$

$22 / 11 / 2001$
Beija-flor

Descobrindo
Valdemir e Wellington

Valdemir e Wellington

Usando uma filmadora Handcam, registramos 13 propostas de produção textual, nas quais participou o aluno Valdemir, com 4 de seus colegas ( 4 propostas com Antenor, 2 propostas com Roberto, 4 propostas com Maria e 3 propostas com Wellington), cada uma destas propostas resultando no manuscrito escolar de um poema inventado.

Foram identificados, em todos os processos originários de cada uma destas propostas, $\mathrm{o}$ instante em que um elemento foi enunciado pela primeira vez e será repetido ao longo do processo de escritura, tendo um importante papel na criação textual dos alunos, determinando o que será escrito no texto entregue ao professor. Ou seja, foram mapeadas as ocorrências orais deste termo, e seus elementos associados, até seu registro no manuscrito. Para esta identificação, analisamos em cada processo de escritura o momento em que o professor inicia a proposta de atividade, o momento em que os alunos conversam antes de começarem a escrever (chamamos este momento de "combinação" ${ }^{\text {) }}$ e o momento da formulação do texto, isto é, quando estão efetivamente grafando na folha de papel o poema a ser entregue ao professor.

Escolhemos dois destes processos ( $1^{\circ}$ processo e $6^{\circ}$ processo) para ilustrar o modo como os tipos de relações associativas e os elementos recuperados da memória se articulam durante a criação textual destes alunos ${ }^{6}$.

\subsection{Um verso a partir de um poema}

O primeiro poema foi produzido por Valdemir e Antenor, em 14/09/2000. As quatro primeiras linhas do manuscrito a seguir foram copiadas do poema

\footnotetext{
5 Como os trabalhos de Bereiter \& Scardamalia (1987) indicam, os subprocessos de "planejar" e "formular", em escreventes novatos, ocorrem simultaneamente. Para favorecer o "planejamento", o professor solicitava que os alunos "combinassem" o que iriam escrever. A recuperação deste diálogo pela filmadora indica que os alunos não faziam exatamente um planejamento" do que iriam escrever. Em geral, eles tinham uma ideia, sugeriam um tema ou apenas combinavam um verso e, imediatamente, diziam terem acabado de "combinar" o poema.

6 Escolhemos estes processos porque ilustram, de modo significativo, os objetivos deste artigo.
} 
"Raridade", escrito por José Paulo Paes (2000), que o professor colocou na lousa, mas que os alunos não conheciam previamente. A proposta era que eles continuassem a escrever o poema, criando outros versos.

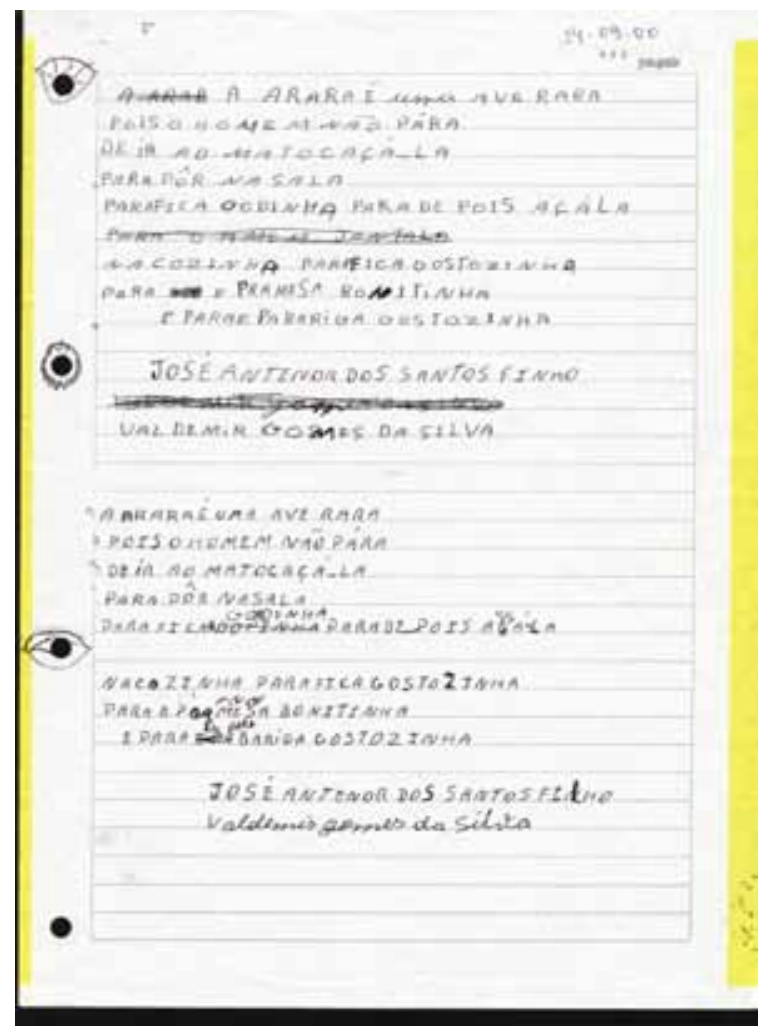

Figura 1: manuscrito "Raridade", de Valdemir e Antenor?.

Os versos criados pela díade foram escritos por Valdemir. Alguns elementos do processo de criação deste manuscrito, como por exemplo, a rasura sobre o verso "para o homem jantá-la", foram analisados em Calil (2008). Aqui, interessa-nos mostrar o momento em que emergiu o termo "assá-la" e

7 Transcrição de acordo com a variante formal, sem as marcas de rasuramento: "A arara é uma ave rara / pois o homem não para / de ir ao mato caçá-la / para por na sala / para ficar gordinha / para depois assá-la / na cozinha / para ficar gostosinha / para ir para mesa bonitinha / para ir para barriga gostosinha”. 
as relações associativas que o geraram até seu registro escrito. O que foi dito por outros alunos e professor antes de sua proferição que possa estar relacionado aos tipos de relações propostas por Suenaga? Quem disse pela primeira vez "assá-la"? Depois de enunciada, como foi escrita na folha de papel?

Começaremos pela última questão. "Assá-la", escrita como uma só palavra e com "ç", compõe o verso "para depois açála" e foi grafada por Valdemir entre os 08:02 e 08:23 minutos. Ela faz rima com "caçá-la" e "na sala", oferecidas, respectivamente, pelos $3^{\circ}$ e $4^{\circ}$ versos copiados. O verso do qual faz parte foi precedido por "para ficar gordinha". Porém, o manuscrito não permite recuperar o tempo de sua formulação. A primeira ocorrência oral de "assá-la" nem se deu depois de "gordinha", como a leitura do manuscrito poderia supor, tampouco coincidindo com o momento de sua efetiva escritura na folha de papel.

Foi logo no inicio da apresentação da proposta pelo professor para toda a classe, que este mesmo aluno, Valdemir, estabeleceu uma primeira forma para este verso e sua rima. A seguir, descrevemos o diálogo entre o professor e os alunos que irá ativar diferentes séries associativas, culminando na associação entre o poema que estava sendo escrito na lousa e o verso criado por Valdemir. Neste caso, pode ser considerado que, já na apresentação da proposta, iniciou-se o processo de escritura colaborativa.

Texto Dialogal 1: Início da apresentação da proposta "Raridade"

\begin{tabular}{l|l} 
CONTEXTO & Após ter declamado para os alunos os poemas “O \\
00:00 - 02:36 & çaseio da poltrona" e "A traça", o professor come- \\
& al, em que os alunos deveriam continuar a escrita \\
de um poema. Enquanto vai declamando os 4 pri- & meiros versos do poema "Raridade", ele os copia \\
na lousa. Ao final do terceiro verso, o professor faz & perguntas aos alunos e comentários sobre algu- \\
mas respostas. A filmadora sendo operada por um \\
auxiliar de pesquisa, no fundo da sala. O foco está \\
aberto e o enquadramento acompanha o movi- \\
mento do professor.
\end{tabular}


$\mathrm{TC}^{1} \quad \mathrm{PROF}$ 00:00 01:07

\begin{tabular}{l|l} 
TC2 & ALUNO $1^{3}$ \\
01:08 01:11 & \\
\hline
\end{tabular}

01:12 01:25
TC3 PROF

Agora... (Professor, de frente para os alunos organizados em semicírculo, olhando para eles e andando pela sala com uma folha em que está o poema "Raridade".) eu vou mostrar pra vocês uma outra poesia... uma outra poesia ... tá? A gente vai discutir essa poesia ...aí a gente de novo... ééé ...ai vai pra uma outra atividade pra gente escrever, tá? Essa poesia... Eu vou começar... Eu vou fazer o começo da poesia... e vocês vão continuar a escrita da poesia. Tá bom? (Indo para a lousa. Escrevendo e falando o que está escrevendo. Alguns alunos repetem o que o professor diz.) $A[\mathrm{a}]^{2}$... a arara[arara] ... é[é]... uma[uma] ... ave[ave]... [rara] (Lendo o verso escrito no quadro.) A arara é uma ave rara. (Iniciando o segundo verso na linha debaixo.) Pois[pois]... o homem[o homem]... pois o homem não para[não pára]... pois o homem não para... (Indo escrever o terceiro verso em outra linha.) De ir[de ir]... de ir... pois o homem não para de ir ao mato[ao mato]... (Pequena pausa. Parando de escrever, perguntando como poderia terminar este verso.) ...fazer o quê??.."

[Inaudível, mas o professor recupera o que o aluno disse.]

(Recuperando e repetindo o que disse o aluno e escrevendo 'caçá-la..) ...caçá-la [caçá-la]. Muito bem. (Comentando sobre a rima.) Pra combinar, né?! (Relendo.) ...pois o homem não para de ir ao mato caçá-la... para[para]... (Repetindo.) para... pôr[pôr na]...

TC4
01:26 01:27

TC5 PROF

01:28 01:32

\section{TC6}

01:33 01:34

TC7

ALUNO 2 ...na gaiola.

01:35 01:36

TC8

01:37 01:39

\author{
ALUNO 3 Comê-la. Caçá-la.
}

(Perguntando.) Combina 'na gaiola'? (Pequena pausa.) Para pôr?

VALDEMIR e (Respondendo.) Na gaiola.

aluno 2
PROF
O poeta usou uma outra palavra. 
TC9

PROF
01:40 02:00

(Repetindo.) Comê-la... caçá-la? Ele colocou...

(Lendo.) para pôr na... sala[sala]. Sala. (Relendo os versos escritos na lousa.) A arara é uma ave rara... pois o homem não para... de ir ao mato caçá-la... para pôr na sala. (Perguntando.) A arara vocês conhecem, não conhecem?

\begin{tabular}{|c|c|c|}
\hline $\begin{array}{l}\text { TC10 } \\
\text { 02:01 02:02 }\end{array}$ & ALUNOS & Conheço. Conheço. Conhecemos. \\
\hline $\begin{array}{l}\text { TC11 } \\
02: 02 \text { 02:04 }\end{array}$ & ALUNO 4 & É aquele pássaro azul, né?! \\
\hline $\begin{array}{l}\text { TC12 } \\
\text { 02:03 02:06 }\end{array}$ & PROF & $\begin{array}{l}\text { Isso. Isso. É um pássaro grande colorido, né? Bo- } \\
\text { nito. }\end{array}$ \\
\hline $\begin{array}{l}\text { TC13 } \\
02: 0602: 10\end{array}$ & $\begin{array}{l}\text { ALUNOS E } \\
\text { PROF }\end{array}$ & $\begin{array}{l}\text { (Alunos falando e professor repetindo.) Azul... } \\
\text { vermelho... amarelo... verde... }\end{array}$ \\
\hline $\begin{array}{l}\text { TC14 } \\
02: 1102: 15\end{array}$ & PROF & $\begin{array}{l}\text { Legal, legal, legal. E os caçadores vão lá caçá-la... } \\
\text { Pra? }\end{array}$ \\
\hline $\begin{array}{l}\text { TC15 } \\
02: 1602: 17\end{array}$ & ALUNO 1 & (Respondendo.) Botar na sala. \\
\hline $\begin{array}{l}\text { TC16 } \\
02: 17 \text { 02:21 }\end{array}$ & PROF & $\begin{array}{l}\text { (Repetindo.) Botar na sala. (Sugerindo.) Pra enfei- } \\
\text { tar a sala. Pra por na gaiola... pra prender... }\end{array}$ \\
\hline $\begin{array}{l}\text { TC17 } \\
02: 2102: 22\end{array}$ & ALUNO 3 & Pra comer. \\
\hline $\begin{array}{l}\text { TC18 } \\
02: 2202: 23\end{array}$ & PROF & $\begin{array}{l}\text { (Repetindo.) Pra comer. (Comentando.) Não sei se } \\
\text { carne de arara é boa. }\end{array}$ \\
\hline $\begin{array}{l}\text { TC19 } \\
02: 23 \text { 02:25 }\end{array}$ & VALDEMIR & (Propondo um verso.) Botar na sala para assá-la. \\
\hline $\begin{array}{l}\text { TC20 } \\
02: 25 \text { 02:26 }\end{array}$ & PROF & $\begin{array}{l}\text { (Olhando e apontando para Valdemir.) Botar... } \\
\text { Ah, como é que é? }\end{array}$ \\
\hline $\begin{array}{l}\text { TC21 } \\
\text { 02:27 02:30 }\end{array}$ & VALDEMIR & $\begin{array}{l}\text { (Repetindo. Professor olhando e acompanhando o } \\
\text { ritmo da fala do aluno com movimento do braço.) } \\
\text { Botar na sala... para... assá-la. }\end{array}$ \\
\hline $\begin{array}{l}\text { TC22 } \\
02: 3102: 36\end{array}$ & PROF & $\begin{array}{l}\text { (Surpreso.) Francamente. Muito bem. (Repetindo.) } \\
\text { Botar na sala... para assá-la. (Elogiando.) Legal. }\end{array}$ \\
\hline
\end{tabular}

Legenda da tabela: $1 \mathrm{TC}=$ Tempo cronometrado.

2 Os termos entre colchetes indicam o que o professor escreve na lousa, ao mesmo tempo em que fala com os alunos.

3 Quando não é possível recuperar o nome do aluno que estava falando, optamos por indicá-lo apenas por "aluno". 
O professor lê em voz alta os versos iniciais do poema "Raridade", na medida em que os escreve na lousa. Ao final do registro do $3^{\circ}$ verso copiado, logo após ter falado e escrito "pois o homem não para de ir ao mato", o professor pergunta "para fazer o quê?", iniciando um jogo associativo e criativo junto aos alunos. Aos 01:12 minutos (TC3) o professor repete a palavra "caçá-la" que parece ter sido dita por um aluno, coincidindo com o que escreveu o poeta [“de ir ao mato caçá-la”]. Neste verso, é possível observar que dois tipos de associações podem aí estar interferindo simultaneamente para a sua proferição: uma associação semântica entre "caçar" e os termos "ave", "arara" e "homem", e a segunda, associação fônica, em que o fonema /a/, presente nas palavras "arara", "rara" e "para", repete-se em "caçá-la". Além disso, observamos que a forma verbo-pronominal "caçá-la” mantém a solidariedade sintagmática com "ir ao mato", o que poderia ser interpretado como uma forma de associação entre significado e significante que se alinha gramaticalmente.

Continuando a copiar o poema na lousa, o professor profere, em voz alta, o início do verso seguinte "para por.... Outro aluno, mantendo o jogo associativo iniciado anteriormente, completa o verso propondo "na gaiola". Neste ponto, abre-se outra série associativa, tendo novamente os termos "ave" e "arara" como eixo semântico estabilizador.

Vale dizer que as séries associativas formadas pelos tipos de relações em torno de "caçá-la" e "na gaiola" resgatam uma prática cultural corrente entre estes alunos. Tanto "caçar", quanto "gaiola" são termos ligados à memória semântica destes alunos da periferia de Maceió que têm por hábito "caçar passarinhos" para prendê-los em "gaiolas". Ilustramos esta prática com imagens capturadas nas ruas de Maceió.
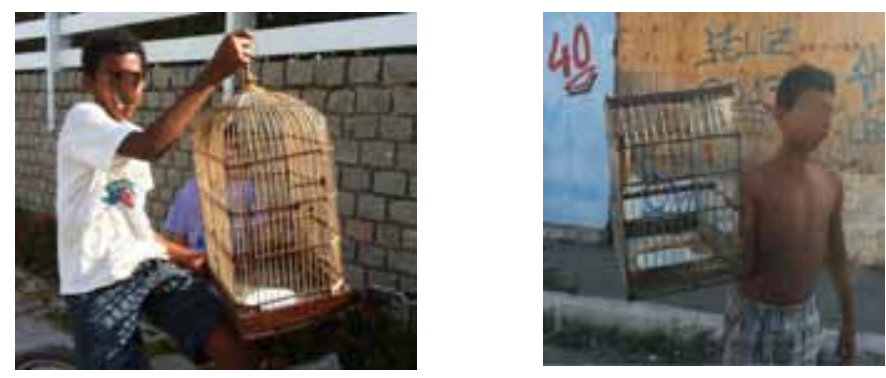

Figura 2: Meninos passeando com passarinhos na cidade de Maceió. (Imagens do autor) 
O professor recusa esta associação semântica dizendo que "não combina" e, em seguida, no TC7 (01:35 - 01:36, ele diz: "o poeta usou outra palavra". Um aluno retoma a série associativa com "caçá-la", acrescentando "comê-la". Ao manter o uso do pronome "la", tem-se não somente relação associativa por significado (tipo 2) entre "caçar" e "comer", mas também relação associativa por significado e significante (tipo 1), em que há solidariedade sintagmática entre a forma verbo-pronominal "caçá-la" e "comê-la".

O fluxo associativo é interrompido com o professor repetindo o que escreveu o poeta: "na sala", o que se encaixa na série associativa já aberta pela presença de "na gaiola", dita antes por outro aluno.

Ao final deste TC9 (01:40 - 02:00), o professor destaca o termo "arara" e, logo em seguida, suas características: "pássaro grande", "colorido" e "bonito". Esta associação semântica com "arara” abre nova série de associações, ocorridas entre TC11 e TC13, com os alunos dando continuidade ao dizerem as cores da arara: azul, vermelho, amarelo, verde.

Logo após repetir o que os alunos disseram, o professor substitui "homem" por "caçadores" (TC14), retomando o jogo associativo a partir de "caçá-la para”. Este enunciado é completado, por um aluno e pelo próprio professor até $\mathrm{o}$ TC18, por termos que mantêm as séries associativas em curso que culmina no enunciado "Não sei se carne de arara é boa". Temos então as seguintes séries associativas:

- $\quad$ Série associativa “a”: ave, arara, pássaro...

- Série associativa "b”: caçar/caçá-la, prender, comer/comê-la, carne...

- Série associativa "c": na sala, na gaiola...

- Série associativa "d": colorida, bonita, enfeitar...

Estas séries associativas não podem ser interpretadas isoladamente, como se fossem estabelecidas termo a termo, ou em uma única direção. Para se entender o processo que as gerou, tem que se levar em conta o processo enunciativo e textual em curso. Elas são constituídas a partir do fluxo do dizer e sofrem a interferência simultânea dos três tipos de associação. A última associação que iremos analisar ilustra de modo particular esta asserção. 
Detendo-se no efeito de sentido entre "comer" e "arara", o professor destaca a associação semântica com "comida": "não sei se carne de arara é boa", enunciado que não deixa de trazer um certo estranhamento com a associação feita pelo aluno. Neste instante, aos 02:23 minutos (TC19), Valdemir, aluno que irá escrever o manuscrito cujo processo analisamos, propõe uma continuação do poema, a partir do que está sendo dito pelo professor e por seus colegas: "E os caçadores vão lá caçá-la para... botar na sala... para assá-la... Ao dizer "botar na sala para assá-la”, o aluno, ao contrário do que o enunciado anterior do professor sugere, não parece estar propondo que se deve "assar" e "comer" a arara. E muito menos, "assar a arara na sala", o que não teria certamente muito sentido. Este verso, e particularmente "assá-la", concentra as séries associativas estabelecidas anteriormente, com o ganho criativo de haver aí um jogo fônico com "na sala" e "caçá-la", respondendo, não à literalidade semântica da ação de se "assar a arara", mas a uma das características mais importantes deste tipo de gênero textual: a homofonia. $\mathrm{O}$ sintagma "para assá-la" foi registrado durante a constituição deste "manuscrito oral", ainda nos primeiros minutos da apresentação da proposta pelo professor e interação com seus alunos. Contudo, ele foi grafado quase $6 \mathrm{mi}$ nutos depois, praticamente sem alteração: "para depois assá-la".

Foi a relação associativa do tipo 3, associação por significante, que parece se impor na enunciação deste termo. Porém, esta relação, assim como os tipos 1 e 2, não ocorre desarticuladamente ou isoladamente. Ela parece ser o resultado da articulação entre as séries associativas anteriores, integrando-se na cadeia sintagmática e preservando, em certa medida, a unidade de sentido do texto.

Isso pode ser observado através da relação de continuidade semântica entre os termos "ave", "arara", "pássaro", "caçar", "comer", "carne” e... "assar". A relação por significado e significante está marcada na contiguidade das formas verbais "caçá-la" e "assá-la", assim como na construção "preposição + verbo (infinitivo)": "para por", "para botar", "para prender”, "para enfeitar", "para comer" e... "para assar". 


\subsection{Dois poemas em um poema}

A filmagem do dia 31/05/2001 registrou o $6^{\circ}$ processo de escritura de um poema inventado, da qual participaram Valdemar e Roberto. Na proposta de produção, conforme sugerido pelo projeto didático "Poema de Cada Dia", o professor retomou o poema "A Traça”, de Guto Lins (1999), já conhecido pelos alunos, e o escreveu noa lousa. Este poema serviu como referência para o poema a ser criado.

\section{A TRAÇA}

Guto Lins

Traça tudo

O que na frente encontrar

$\underline{\text { Sua calça de veludo }}$

$\underline{\text { Seu }}$ casaco sobretudo

E o que tiver para traçar

Só não traça a sua meia suja

Aquele troço esquisito

Que você esqueceu de lavar.

Diferentemente da proposta analisada acima, neste momento o poema foi declamado e foram feitos alguns comentários sobre o jogo homonímico proposto pelo poeta. Em seguida, a partir de sugestões dadas pelos alunos, o professor escreveu na lousa possíveis títulos "O piolho", "A anta", "A barata”, "A pulga", "O gato", "O cachorro", "O mosquito", "O rato", "A cobra”, "O sapo,, “O coelho", "O jacaré”, "A formiga”, "O calango” e pediu para cada dupla escolher um deles para criar um poema. Aos 04:44, Valdemir e Roberto dizem para o professor que escolheram "A formiga". Foi entregue a folha de papel e a caneta para a díade. Até os 17:56 Valdemir, com a ajuda de Roberto, havia escrito: 


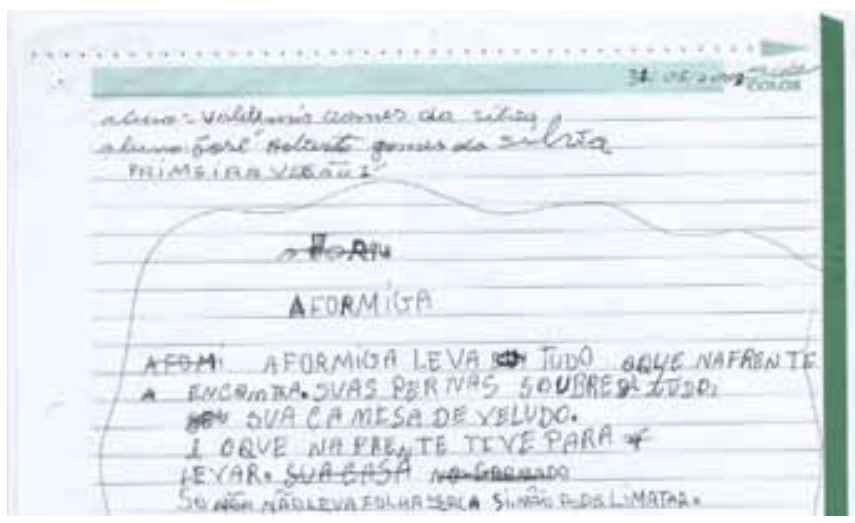

Figura 3: Fragmento 1 do manuscrito "A Formiga", de Valdemir e Roberto.

Os itens sublinhados na variante formal a seguir, e no poema referência citado, destacam a semelhança entre estes dois poemas.

\section{A FORMIGA}

\section{Valdemir e Roberto}

A formiga leva tudo

O que na frente encontrar

$\underline{\text { Suas pernas sobretudo }}$

Sua camisa de veludo

E o que na frente tiver para levar

Só não leva folha seca

Senão pode lhe matar.

Como se tem mostrado em diferentes análises de textos inventados e escritos por escreventes novatos (KRESS, 1997; DYSON, 2003; CALIL, 2012), é recorrente a presença de elementos gráficos, de textos conhecidos e fragmentos textuais relacionados ao universo letrado e à cultura de seu entorno. Em nosso caso, a díade usou o poema-referência "A traça" como apoio, mantendo sua estrutura e alguns elementos lexicais que sublinhamos nos dois poemas. 
As relações entre o poema "A traça" e "A formiga" são evidentes. Além da repetição de vários elementos lexicais e estruturas sintáticas, tem-se tanto relações semânticas entre "traçar" e "levar", entre "calça", "pernas", "casaco" e "camisa", quanto relações homofônicas entre "só não" e "senão" e entre os verbos "traçar" e "lavar", do poema-referência e "levar" e "matar", do poema dos alunos. De certo modo, a unidade do poema "A formiga" ainda é sustentada pela presença do termo "folha", no penúltimo verso, o qual mantém uma relação de contiguidade semântica entre estes termos. Enfim, o que mostra o manuscrito escolar, produzido até este momento, é uma paráfrase do poema-referência.

Após ter escrito o último verso, Valdemir e Roberto releem em voz alta todo o poema, como se já estivessem terminado de escrevê-lo. Contudo, uma associação inesperada surge logo após sua leitura, concluída aos 18:22 minutos, provocando a continuidade do processo de escritura e a entrada de uma canção no poema "A formiga". Mostraremos o momento em que isso aconteceu e seus efeitos sobre a configuração final do manuscrito.

Texto Dialogal 2: A formiguinha

\begin{tabular}{|c|c|c|}
\hline \multicolumn{2}{|c|}{$\begin{array}{l}\text { CONTEXTO } \\
18: 25-19: 15\end{array}$} & $\begin{array}{l}\text { Após terminarem a leitura do poema que escreve- } \\
\text { ram, "A formiga", os alunos resolvem continua-lo }\end{array}$ \\
\hline $\begin{array}{l}\text { TC1 } \\
18: 2518: 27\end{array}$ & ROBERTO & (Com ênfase.) Acabou! \\
\hline $\begin{array}{l}\text { TC2 } \\
18: 2518: 28\end{array}$ & VALDEMIR & $\begin{array}{l}\text { (Relendo o último verso.) Senão... senão pode me } \\
\text { matar. }\end{array}$ \\
\hline $\begin{array}{l}\text { TC3 } \\
18: 2918: 33\end{array}$ & ROBERTO & $\begin{array}{l}\text { Aí bota assim... a... a formiga corta a folha e car- } \\
\text { rega. }\end{array}$ \\
\hline $\begin{array}{l}\text { TC4 } \\
18: 3318: 36\end{array}$ & $\begin{array}{l}\text { ROBERTO E } \\
\text { VALDEMIR }\end{array}$ & (Pausa.) \\
\hline $\begin{array}{l}\text { TC5 } \\
18: 3718: 42\end{array}$ & VALDEMIR & $\begin{array}{l}\text { (Repetindo.) E a formiga corta a folha... e carrega } \\
\text { para dentro do buraco. Uma deixa... }\end{array}$ \\
\hline $\begin{array}{l}\text { TC6 } \\
18: 43 \text { 18:45 }\end{array}$ & ROBERTO & ...a outra leva. \\
\hline
\end{tabular}




\begin{tabular}{|c|c|c|}
\hline $\begin{array}{l}\text { TC7 } \\
18: 4418: 46\end{array}$ & VALDEMIR & E uma deixa... a outra leva... \\
\hline $\begin{array}{l}\text { TC8 } \\
18: 4618: 49\end{array}$ & ROBERTO & E ninguém pode... e ninguém pode deixar. \\
\hline $\begin{array}{l}\text { TC9 } \\
18: 5018: 57\end{array}$ & VALDEMIR & $\begin{array}{l}\text { (Relendo os dois últimos versos.) Só não leva } \\
\text { folha seca... senão pode lhe matar. }\end{array}$ \\
\hline $\begin{array}{l}\text { TC10 } \\
18: 5818: 59\end{array}$ & ROBERTO & Só não... \\
\hline $\begin{array}{l}\text { TC11 } \\
18: 59 \text { 19:01 }\end{array}$ & VALDEMIR & E quando uma... formiguinha deixa... \\
\hline $\begin{array}{l}\text { TC12 } \\
\text { 19:02 19:05 }\end{array}$ & ROBERTO & $\begin{array}{l}\text {...quando uma deixa... quando uma deixa... a ou- } \\
\text { tra leva. }\end{array}$ \\
\hline $\begin{array}{l}\text { TC13 } \\
\text { 19:06 19:11 }\end{array}$ & VALDEMIR & $\begin{array}{l}\text { (Olhando e apontando com a caneta para a linha } \\
\text { abaixo do último verso escrito.) A formiguinha... } \\
\text { (Relendo o verso anterior.) ...senão pode lhe ma- } \\
\text { tar... (Olhando para Roberto.) A formiguinha... } \\
\text { corta a folha e carrega. }\end{array}$ \\
\hline $\begin{array}{l}\text { TC14 } \\
19: 1219: 13\end{array}$ & ROBERTO & Quando uma deixa... \\
\hline $\begin{array}{l}\text { TC15 } \\
\text { 19:12 19:15 }\end{array}$ & VALDEMIR & $\begin{array}{l}\text { Quando uma deixa... (Olhando para Roberto.) ...a } \\
\text { outra leva. }\end{array}$ \\
\hline
\end{tabular}

Roberto, ao dizer “Acabou!', no TC1 (18:25 - 18:27 minutos), logo após a leitura feita pelo colega Valdemir do que haviam escrito até o momento, parecia constituir uma unidade suficiente para se concluir o poema. Contudo, é ele mesmo, Roberto, quem propõe sua continuidade, enunciando " $A i ́$ bota assim... a... a formiga corta a folha e carrega", como se fosse a proposta de um novo verso a ser acrescentado no poema já escrito. A repetição do sintagma nominal "a formiga" está relacionada ao paralelismo semântico e sintático característico da poesia. A entrada de "corta" teria, por sua vez, uma relação associativa sintagmática com "folha" e ainda uma relação por continuidade semântica, dado que uma das características deste inseto, certamente conhecida por estes alunos, é "cortar folhas".

No entanto, o que surpreende neste instante (18:29 - 18:33 minutos, TC3) é a entrada de um fragmento de outro texto conhecido. Quando Ro- 
berto propõe “...corta a folha e carrega", inicia-se a recuperação de uma canção religiosa, cujo conteúdo compartilham. Valdemir, logo após uma pequena pausa (TC4), retoma o verso e o complementa " $E$ a formiga corta a folha... e carrega para dentro do buraco. Uma deixa..." e Roberto o conclui “...a outra leva”. Os dois alunos conhecem a música infantil religiosa que está sendo lembrada.

\section{A formiguinha}

A formiguinha corta a folha e carrega,

Quando uma deixa a outra leva! (bis)

\section{Coro}

Deus não quer preguiçoso em sua obra, (3 vezes)

Porque se não, o tempo sobra!

Oh! que mistério glorioso,

A formiguinha ensinando ao preguiçoso! (bis)

Geralmente cantada e ensinada nos encontros evangélicos da igreja que frequentam, a canção da formiguinha faz parte do universo cultural destes alunos. Eles, juntos, relembram a canção, cujos versos serão escritos no poema, como se fossem eles que os tivessem criado. Neste momento do desenvolvimento da escritura, parece não ser muito claro para os escreventes que "escrever um poema inventado" supõe escrever algo que seja inventado por eles. Nossos dados indicam que, para os alunos recém alfabetizados, "inventar" um texto se faz a partir da recuperação de fragmentos de textos conhecidos. Não há indícios claros de que este processo seja feito intencionalmente ou premeditadamente.

Este fato, no entanto, é pouco relevante para este estudo. O que interessa aqui é compreender as relações que contribuíram para a entrada do fragmento da música Gospel "A formiguinha" no poema que, aparentemente, já havia sido terminado. $\mathrm{O}$ que parece ter favorecido a associação feita por Roberto, ativando a memória semântica compartilhada da canção gospel, foi a aproximação entre "a formiga" do poema já escrito e "a 
formiguinha" daquela canção aprendida na igreja. Entretanto, o elo estabelecido, como já mostramos na análise do poema "Raridade", não é de uma palavra com outra, mas de uma série associativa com outra. Apesar de o nó associativo estar no termo "formiga", o que vem de imediato da memória dos alunos são os dois primeiros versos da canção "A formiguinha”, praticamente sem alteração.

Após a aproximação do professor, quando Valdemir relê o que escreveram e lhe diz o que irá continuar escrevendo, estes versos serão escritos na folha de papel entre os 20:02 e 25:45 minutos. O trecho "para dentro do buraco", apesar de estar semanticamente associado ao conhecimento sobre as ações das formigas, e haver contiguidade sintagmática com o termo "carrega", semelhantemente às relações entre "folha" e "cortar", indicadas acima, foi excluído do poema final, ficando somente os versos conhecidos da canção gospel. Durante este tempo, o verso "A formiguinha corta a folha e carrega" foi rasurado por 3 vezes, antes de ser grafado, finalmente, "A formiguinha corta a folha e carrega / Uma deixa, a outra leva”.

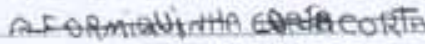

QFOMIAAORAAEINH

AFORM GUINHA GQRTA A FOLATA IARREGA

A FORMIOUINAB CORTA AFOLHA ECQRREUA

UMA DEICHA A QUTRALEVAR OLAA QUEMISTERIO

Figura 4: Fragmento $2^{8}$ do manuscrito "A Formiga", de Valdemir e Roberto.

A presença da palavra "formiga", apesar de ter sido escrita na sua forma diminutiva, reforça a imposição desta associação entre "a formiga" do título do poema e "a formiguinha" da canção Gospel. Vale chamar a atenção para o fato de estes dois versos terem emergidos "em bloco", entre o TC11 e TC12, sem hesitação, reforçando nossa interpretação de que eles já faziam parte do repertório destes alunos. A recuperação da canção gospel continuou até os 27:35 minutos, quando Valdemir, cantarolando-a, conclui a escritura dos

8 Transcrição na variante formal: "A fomiguinha corta corta / A formiguinha corta a folha e / A formiguinha corta a folha e carrega / A formiguinha corta a folha e carrega / Uma deixa, a outra leva". 
dois últimos versos: "olha que mistério glorioso / a formiguinha ajudando o preguiçoso", conforme mostra o fragmento:

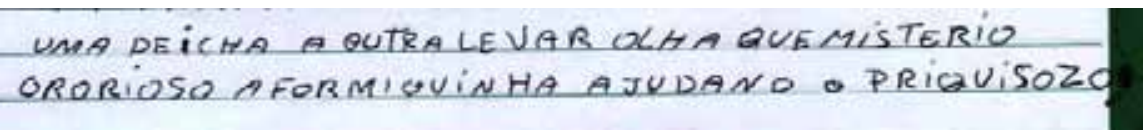

Figura 5: Fragmento $3^{9}$ do manuscrito "A Formiga", de Valdemir e Roberto.

No manuscrito escolar do poema "A formiga", entregue ao professor ao final da proposta de produção textual, observa-se, portanto, a presença de dois poemas conhecidos dos alunos. Na primeira parte, tem-se uma paráfrase do poema "A traça", recuperando elementos dos versos que estavam na lousa. Na segunda parte, foi escrita após o estabelecimento de relações associativas semânticas e homofônicas provocadas pelo termo "formiga", fazendo com que a díade recuperasse da memória de longo prazo compartilhada os versos da canção gospel "A formiguinha", ensinada na igreja frequentada.

\section{CONCLUSÃO}

Tanto os estudos sobre a gênese de obras literárias, quanto os experimentos sobre produção textual em Psicologia Cognitiva mostram que há uma recursividade própria da escritura, em que a memória do escrevente tem um papel essencial na construção do texto. A interpretação daqueles processos de criação textual, a partir das relações associativas propostas por Suenaga, procurou articular dois objetos inter-relacionados, porém distintos: a escritura (em tempo real) colaborativa e o funcionamento da língua. Apesar de terem em comum a dimensão linear da cadeia sintagmática, o caráter espaciotemporal, a recursividade e sua condição didático-interacional e co-enunciativa, são elementos essenciais para a compreensão da gênese destes manuscritos escolares.

Procuramos mostrar a constituição de redes associativas, destacando a formação de alguns elos entre os tipos de associações e os conteúdos recupe-

9 Transcrição na variante formal: "uma deixa a outra leva / olha que mistério glorioso / a formiguinha ajudando o preguiçoso. 
rados de "séries mnemônicas virtuais". Estas duas análises destacam o modo como se formam estas redes e a recuperação de conteúdos da memória dos escreventes, resultando na criação de versos que o manuscrito acabado não permite recuperar. Para estes escreventes, o estabelecimento de um determinado termo parece atuar como ponto de atração e fixação para o qual convergem outras associações, fazendo dele um nó resistente ao apagamento, substituição ou deslocamento, assemelhando-se ao que Scardamalia \& Bereiter (1987) chamaram de knowledge telling strategy.

Na dinâmica criativa destes poemas, alguns pontos merecem ser destacados:

- A importância e complexidade das relações associativas, do universo cultural e da memória dos escreventes no processo de criação textual em sala de aula.

- $\quad$ O modo como os tipos de relações associativas se articulam entre si, sugerindo a impossibilidade de haver o estabelecimento de apenas um tipo ou uma série associativa durante estes processos de produção textual.

- A coenunciação efetivada durante a escritura colaborativa a dois, em contexto escolar, estabelece, intersubjetivamente, elos associativos que se afastam, se aproximam, se interrompem, mudam a direção textual..., através dos tipos de relações que se sobrepõem umas sobre as outras.

- $\quad$ O manuscrito final não pode resgatar a dinâmica desta rede, mas preserva o seu resultado, apagando, em parte, as conexões entre os elementos que o constituíram.

Por fim, gostaríamos de destacar um dos pontos mais importantes da discussão apresentada. Ainda que as propriedades do gênero textual e as possibilidades de encadeamento sintagmático possam impor limites ao que será escrito, ainda que estes escreventes sejam novatos, as relações associativas, por depender do "espírito" do escrevente, carregam consigo o imprevisível (FELIPETO, 2008), dimensão incontornável do dizer, já sugerida por Saussure. 
Os grupos formados por associação mental não se limitam a aproximar os termos que apresentem algo em comum; o espírito capta também a natureza das relações que os unem em cada caso e cria com isso tantas séries associativas quantas relações diversas existam. [...] Por conseguinte, existe tanto comunidade dupla de sentido e da forma como comunidade de forma ou de sentido somente. Uma palavra qualquer pode sempre evocar tudo quanto seja suscetível de ser-lhe associado de uma maneira ou de outra.

Enquanto um sintagma suscita em seguida a ideia de uma ordem de sucessão e de um número determinado de elementos, os termos de uma família associativa não se apresentam nem em número definido nem numa ordem determinada. [...] Um termo dado é como o centro de uma constelação, o ponto para onde convergem outros termos coordenados cuja soma é indefinida.

(SAUSSURE, 1987, p.145-146)

Não obstante a dinâmica associativa ser marcadamente imprevisível, sem que seja possível prever qual relação será estabelecida a cada ato enunciativo, parece ser legítimo se perguntar qual dos dois processos descritos e analisado poderia ser considerado mais criativo ${ }^{10}$. Poderíamos responder que foi o primeiro. A associação fônica produzida por Valdemir está inserida ao intenso jogo de sentidos iniciado desde da apresentação da proposta pelo professor, produzindo certo efeito lúdico no "texto em construção". A comparação entre os dois processos indicaria uma significativa diferença

${ }^{10}$ A complexidade desta noção e as relações específicas com os objetos aos quais ela está atrelada, não permite a apresentação de uma definição comum a todos eles. Ou seja, ao mesmo tempo em que o termo "criativo" possa se referir a qualquer objeto produzido pelo homem (escultura, pintura, canção, poema, filme, propaganda de TV, enunciado de criança, webpage, videogame, uma ideia...) suas definições são heterogêneas, difusas e vagas. Por esta razão, entendemos simplesmente como "criativo" a conexão inesperada entre elementos diversos, ao mesmo tempo advindo do que já é conhecido e apresentando algo novo, diferente do que já conhecido. (LEHRER, 2012; GRAINGER, GOOUCH; LAMBIRTH, 2005). 
"criativa" entre este poema e o poema "A formiga". Neste poema, os alunos não chegam a propor um "novo" texto. Eles limitam-se a parafrasear o poema-referência ("A Traça”) e a recuperar versos de uma canção (A formiguinha), já conhecida.

Neste sentido, poderíamos estabelecer como hipótese que a criatividade, produzida nestes contextos didáticos de produção textual, estaria relacionada à riqueza e diversidade dos tipos, das séries e redes associativas, colocando em relação elementos recuperados da memória e da cultura, advindos de domínios distantes. Contudo, se esta dimensão da criação textual em sala de aula for produtiva, surge aí uma questão: em que medida as orientações curriculares brasileiras atuais, preocupadas com a aprendizagem instrumental dos gêneros textuais, favoreceriam esta dimensão? Importante ponto a ser explorado em trabalhos futuros.

\section{REFERÊNCIAS}

BEREITER, Carl; SCARDAMALIA, Marlene. The psychology of written composition. Hilsdale. New Jersey: Lawrence Erlbaum Associates, 1987.

BIASI, Pierre-Marc de. Génétique des textes. Paris: CNRS Editions, 2011.

BORÉ, Catherine. Modalités de la fiction dans l'écriture scolaire. Paris: Éditions l'Harmattan, 2010.

CALIL, Eduardo. A construção de Zonas de Desenvolvimento Potencial em um contexto pedagógico. 1991. Dissertação (Mestrado)- Faculdade de Educação-Universidade de São Paulo, 1991.

CALIL, Eduardo The construction of the zone of proximal development in a pedagogical context. In: Neil Mercer and César Coll (Ed.). Explorations in Socio Cultural Studios: Teaching, Learning and interaction. v. 3. Madrid: Fundación Infancia y Aprendizaje, 1994. p. 93-98. 
CALIL, Eduardo. Poema de Cada Dia. Projeto didático. Disponível em: http://portal.mec.gov.br/seb/arquivos/pdf/Poema.PDF, março de 2001.

CALIL, Eduardo. Escutar o invisível: escritura e poesia na sala de aula. Campinas: Editora Unesp/Funart, 2008.

CALIL, Eduardo. Dialogues between two pupils during the process of writing a fictional story Verbal erasures and their forms of representation In: Fr. Cooren; Al. Létourneau (Ed.) . (Re)presentations and Dialogue. 1 ed.. Amsterdam: John Benjamins Publishing Company, 2012. p. 325-341.

DOQUET, Claire. L'écriture débutant: pratiques scriptuales à l'école élémentaire. Rennes: Presses Universitaires de Rennes, 2011.

DYSON, Anne Haas. The brothers and sisters learn to write popular literacies in childhood and school cultures. New York: Teachers College Press, 2003.

FABRE, Claudine. Les brouillons d'écoliers ou l'entrée dans l'écriture. Grenoble: / L'Atelier du Texte, 1990.

FABRE-COLS, Claudine. Brouillons scolaires et critique génétique : nouveaux regards, nouveaux égards ? Linx, n. 51, p. 13-24, 2004. Disponível em http://linx.revues.org/160. Acesso em: 10 out. 2012.

FELIPETO, Cristina. Rasura e equívoco no processo de escritura na sala de aula. Londrina: EDUEL, 2008.

FENOGLIO, Irène. Du texte avant le texte. Formes génétiques et marques énonciatives de pré-visions textualisantes. Langue française, Paris, Larousse, 155, p. 8-34, 2007.

FIAD, Raquel Saleh. Indices de la présence de l'auteur dans des textes écrits par des enfants: marques de meta-énonciation. In: Catherine Boré \& Eduar- 
do Calil (Ed.). Lécole, l'écriture et la création. Paris: Ed. Bruylant-Academia, 2013. p. 251-268.

FRADET, Marie-Françoise. Ecriture de fiction, interactions et apprentissage. In : CONGRÈS MONDIAL DE LINGUISTIQUE FRANÇAIS, 2010, Paris. Anais... Paris: Institut de Linguistique Française, 2010.

GADET, Françoise. Saussure, une science de la langue. Paris: PUF, 1989.

GRÉSILLON, Almuth. Eléments de Critique Génétique: lire les manuscritsmodernes. Paris: Presses Universitaires de France, 1994.

GRAINGER, Teresa; GOOUCH, Kathy; LAMBIRTH, Andrew. Developing voice and verve in the classroom. London: Routledge, 2005.

KELLOGG, R.T. Training writing skills: A cognitive developmental perspective. Journal of writing research, 1(1), p. 1-26, 2008.

KRESS, Gunther. Before writing: rethinking the paths to literacy. London: Routledge, 1997.

LEBRAVE, Jean-Louis. Lecture et analyse des brouillons. Langages, 69, p. 11-23, 1983,

LEHRER, Jonah. Imagine: how creativity works. London: Canongate Books, 2012.

LINS, Guto. Q Barato ou a metamorfose. São Paulo: Ediouro, 1999.

MAHER, Rudolf. De la textualité des brouillons : prolégomènes a un dialogue entre linguistique et génétique des textes. Modèles Linguistiques: génétique de la production écrite et linguistique. Tome XXX, vol. 59. Toulon : Editions des Dauphins, 2009. p. 51-70. 
PAES, Jose Paulo. Olha o bicho. São Paulo: Ática, 2000.

SAUSSURE, Ferdinand de. Cours de Linguistique Générale. Édition Tullio de Mauro. Paris: Payot, 1982.

SAUSSURE, Ferdinand de. Curso de Linguística Geral. São Paulo: Cultrix, 1987.

SUENAGA, Akatane. Saussure, un système de paradoxes : langue, parole, arbitraire et inconscient. Limoge: Lambert-Lucas, 2004. 